Article

\title{
Structure and Sound Absorption Properties of Spiral Vane Electrospun PVA/PEO Nanofiber Membranes
}

\author{
Huan Liu 1,2,* and Baoqi Zuo ${ }^{1,2, *}$ \\ 1 National Engineering Laboratory for Modern Silk, Soochow University, Suzhou 215123, China \\ 2 College of Textile and Clothing Engineering, Soochow University, Suzhou 215021, China \\ * Correspondence: lh5215006@163.com (H.L.); bqzuo@suda.edu.cn (B.Z.); Tel.: +86-153-7003-8962 (H.L.); \\ +86-130-6388-6138 (B.Z.)
}

Received: 2 January 2018; Accepted: 12 February 2018; Published: 17 February 2018

\begin{abstract}
Noise pollution has become one of the four major pollution issues in the world and has drawn much attention recently. Controlling the sound source and using sound-absorbing materials reasonably is considered an effective way to reduce noise. Due to the high porosity and specific surface area, nanofibers membrane is widely used in the field of the sound absorption. Polyvinyl alcohol (PVA) and Polyethylene oxide (PEO) are both water-soluble polymers with good film-forming properties that can be mixed in any proportion. In this paper, nanofiber membranes were prepared by spiral vane electrospinning with different contents of PVA and PEO. The nanofibers membranes were characterized by Fourier Transform-Infrared (FT-IR), X-ray diffraction (XRD), 3D-M, and scanning electron microscopy (SEM). The sound absorption property of nanofibers membranes and the compositions (nanofiber membranes and needle punched non-woven fabric) were tested with an impedance tube. The results demonstrate that the addition of PEO changed the morphological characteristics and construct of PVA, sound absorption properties had undergone great changes.
\end{abstract}

Keywords: Polyvinyl alcohol; Polyethylene oxide; nanofiber membrane; sound absorption property

\section{Introduction}

Noise pollution is becoming an increasingly valued issue in the world [1-3]. Noise does harm to human health and reduces the service life of objects [4-6]. Controlling the sound source and using sound-absorbing materials reasonably are considered effective ways to reduce noise $[7,8]$.

The traditional sound absorption materials have good sound absorption properties at high frequency, while the sound absorption effect at low frequency range is relatively poor [9-12]. In recent years, a variety of light non-woven materials were widely used for reducing noise [13-15]. The poor sound absorption performance of traditional sound-absorbing materials, at low-middle frequency was replenished [16,17]. According to different sound absorption principles, sound-absorbing materials can be generally divided into resonant sound-absorbing structure and porous sound-absorbing structure [18-20]. Sound waves entered into the resonance-absorbing structures resonating within the structure, thereby dissipating large amounts of acoustic energy [21]. Lots of sound waves can enter into the porous materials, then the acoustic energy can be turned into heat or mechanical energy consumed, because of the internal friction, heat conduction, and relaxation between the sound waves and fibers [22,23].

Many sorts of polymers are electrospun into nanofiber membranes. Polyvinyl alcohol (PVA) can completely dissolve in heated water, film easily with well mechanical property, and has attracted intense attention [24-26]. Polyethylene oxide (PEO) belongs to semicrystalline polymer that contains amorphous regions and crystalline phases at room temperature. It dissolves in water at room temperature completely and is widely used because of its high thermal stability and strength $[27,28]$. From the point of the environment, it is considered important that Polyvinyl alcohol (PVA) and 
Polyethylene oxide (PEO) are both water-soluble polymers [29]. Blending is the most straightforward and easy way to get new materials or improve the performance of polymers. Blended polymers generally exhibit superior performance compared to single-component polymer [30,31].

The main purpose of this work is to attain better sound absorption property by modifying PVA nanofibers membranes. With different contents of PEO, morphology of fibers, surfaces, and internal structures of membranes were changed respectively. As a result, the sound absorption performance of blend nanofiber membranes is improved greatly.

\section{Materials and Methods}

Polyvinyl alcohol (1788) and Polyethylene oxide $\left(M_{\mathrm{W}}=1,000,000\right)$ were purchased from Changzhou Fengyuan Textile Assistant Co. Ltd. (Changzhou, China) and Shanghai Liansheng Chemical Co. Ltd. (Shanghai, Chian), respectively. PVA ( $8 \mathrm{wt} \%)$ and PEO (3 wt \%) were blended by electrospinning with different solution mass ratios of 100/0, 90/10, 80/20, and 70/30, respectively. Then the nanofiber membrane was composited with needle-punched nonwovens (DN30D1, $4 \mathrm{~mm}$, Shenzhen Dongfang Nonwove Co. Ltd. (Shenzhen, China)).

Spiral vane electrostatic spinning machine (Kunshan Tongray) (Figure 1), which is composed of a spiral generator, an acceptor and a high-voltage power source. High-voltage power can provide up to $70 \mathrm{KV}$ voltage, strong electric force was produced on the surface of the metal spiral to overcome the surface tension of solution, the solution Taylor cones were stretched into superfine jets. Then water vapor evaporated and formed PVA/PEO nanofibers on the acceptor.

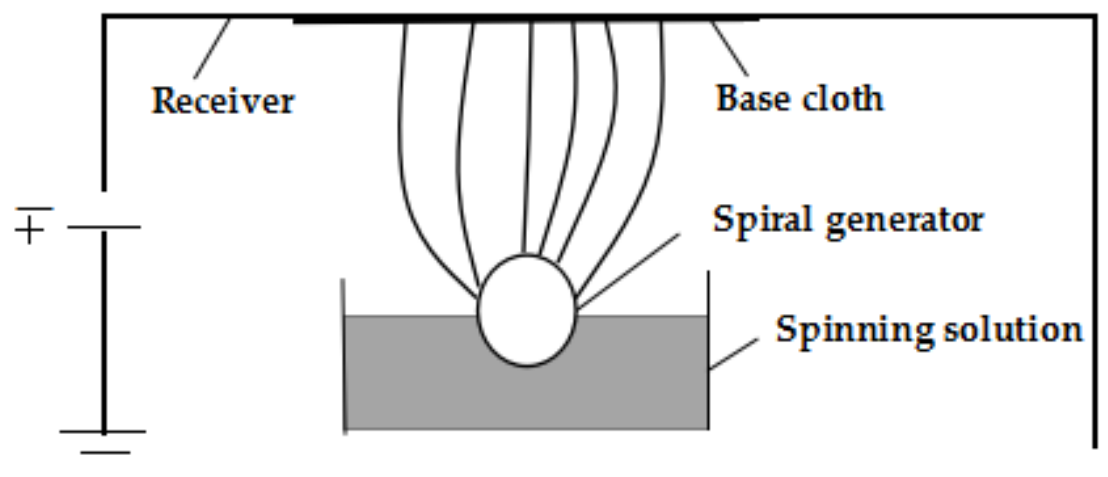

Figure 1. Schematic diagram of spiral vane electrostatic spinning machine.

Fourier Transform-Infrared (FT-IR) transmittance were carried out for different nanofibers membranes by using Fourier transform-infrared spectrormeter (Nicolet5700, Nicolet, Madison, WI, USA) in the spectra range of $4000-800 \mathrm{~cm}^{-1}$. X-ray diffraction (XRD) scans were obtained by using PAN alytical X-Pert Pro MPD XRD system (Chemplex, Palm, FL, USA), the diffraction angle in the range of $5^{\circ}-45^{\circ}$. The morphology of the nanofiber membranes were measured by using scanning electron microscopy (S4800, Hitachi, Tokyo, Japan). The three-dimensional characterization of the nanofiber membranes were tested using a depth of field three-dimensional microscopy system (VHX-1000, OLYMPUS, Osaka, Japan). According to ISO 10534-2:1998 standards, the acoustical properties of samples were measured with a transfer-function method. Sound absorption testing instruments were SW477 and SW422 impedance tube (BSWA Technique Company, Beijing, China) in the range of 80-6300 Hz. Testing conditions: relative temperature $20 \pm 1{ }^{\circ} \mathrm{C}$, relative humidity $65 \pm 2 \%$.

The structure of impedance tube was showed in Figure 2. The impedance tube method is on the basis of the two-microphone transfer-function method. There are sample materials and loudspeakers at both ends of the impedance tube, which is airtight, rigid, and straight. Different frequencies of sound waves are generated by the sound source along the plane to the material direction, the two sound pressure measuring devices near the sample obtain the acoustic transfer function of the signal, 
then the sample's normal incident absorption coefficient is calculated, the sound absorption coefficient spectrum displayed on the computer screen finally.

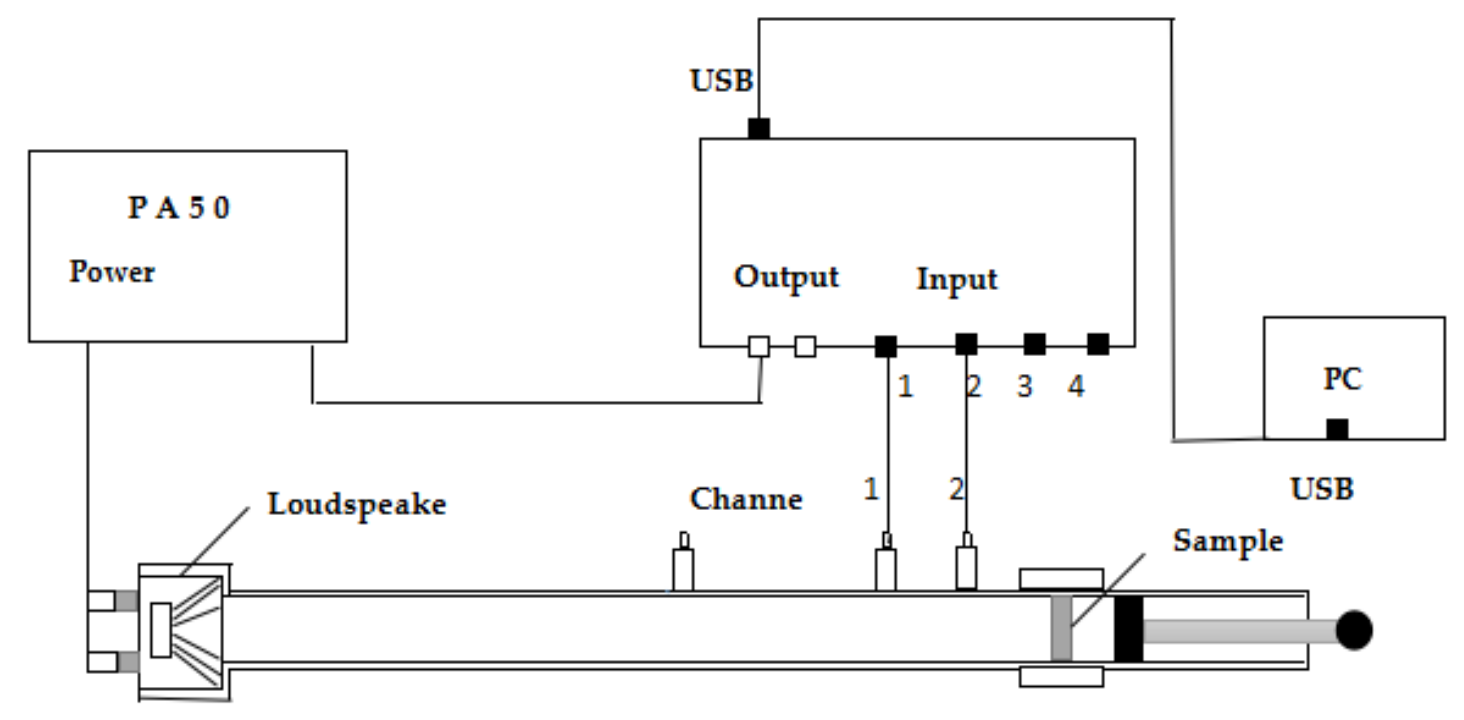

Figure 2. The structure of impedance tube.

\section{Results and Discussion}

\subsection{Fourier Transform-Infrared Analysis}

The FT-IR spectrum was showed in Figure 3. Many characteristic peaks of the pure PVA can be found at $840,954,1093,1427,1736,2940$, and $3349 \mathrm{~cm}^{-1}$. It was obvious that the peaks at 840 , 954 , and $2940 \mathrm{~cm}^{-1}$ was caused by stretching vibration of the functional group of $-\mathrm{CH}_{2}$. The peak at $1093 \mathrm{~cm}^{-1}$ was contribute to the stretching vibration of the functional group of $\mathrm{C}-\mathrm{O}$. The peaks at 1427 and $3349 \mathrm{~cm}^{-1}$ was caused by stretching vibration of the functional group of $-\mathrm{OH}$. The peak at $1736 \mathrm{~cm}^{-1}$ was benefited from the stretching vibration of the functional group of $\mathrm{C}=\mathrm{O}$. It can be seen from Figure 3, the blend membranes possessed the same bands at 840, 954, 1093, 1427, 1736, 2940, and $3349 \mathrm{~cm}^{-1}$. However, the peaks at 1427 and $3349 \mathrm{~cm}^{-1}$ became more gentle with the addition of PEO. Moreover, the sample d appeared the characteristic peak of PEO at $2887 \mathrm{~cm}^{-1}$, which was caused by stretching vibration of the functional group of $-\mathrm{CH}_{2}$.

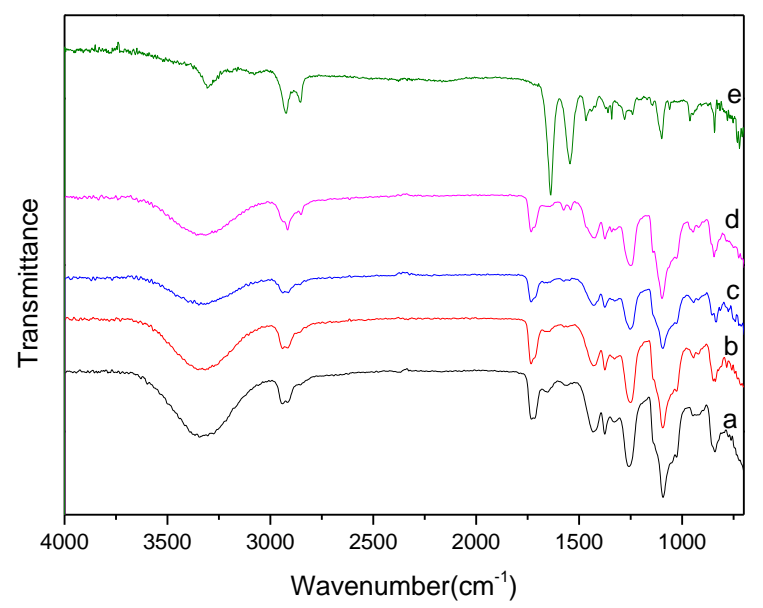

Figure 3. FT-IR of PVA/PEO membranes. (a) 8 wt \% PVA; (b) 8 wt \% PVA/3 wt \% PEO (90/10); (c) $8 \mathrm{wt} \%$ PVA $/ 3$ wt \% PEO (80/20); (d) 8 wt \% PVA/3 wt \% PEO (70/30); (e) 3 wt \% PEO. FT-IR: Fourier Transform-Infrared; PVA: Polyvinyl alcohol; PEO: Polyethylene oxide. 
According to theory, PEO macromolecules with the ultra-high modulus passed through the PVA macromolecular chains, hydrogen bonds were formed between the ether bond of PEO macromolecule and hydroxyl group on the side-group of PVA molecule during the film-forming process [32-34]. Hydrogen bonds between the PVA molecules and the orderly arrangement of PVA molecules were hindered by PEO macromolecules [35]. PEO can increase the intermolecular entanglement rate between fibers, due to its long molecular chain and good viscoelasticity [36,37].

\subsection{X-ray Diffraction Analysis}

X-ray diffraction of pure PVA ( $8 \mathrm{wt} \%)$, PEO (3 wt \%), and PVA/PEO blend films were showed in Figure 4. Pure PEO has two distinct diffraction peaks at $19.2^{\circ}$ and $23.3^{\circ}$, whereas pure PVA has a broader diffraction peak at $19-20^{\circ}$. With the addition of PEO, the diffraction peak at $19-20^{\circ}$ of blend membranes became more obvious, and the characteristic diffraction peak of $\mathrm{PEO}$ at $23.3^{\circ}$ appeared weakly compared to the PVA membrane. However, with the contents of PEO increasing, the diffraction peak at $19-20^{\circ}$ of blend membranes became more gentle. The addition of PEO changed the degree of crystallinity of PVA in some way.

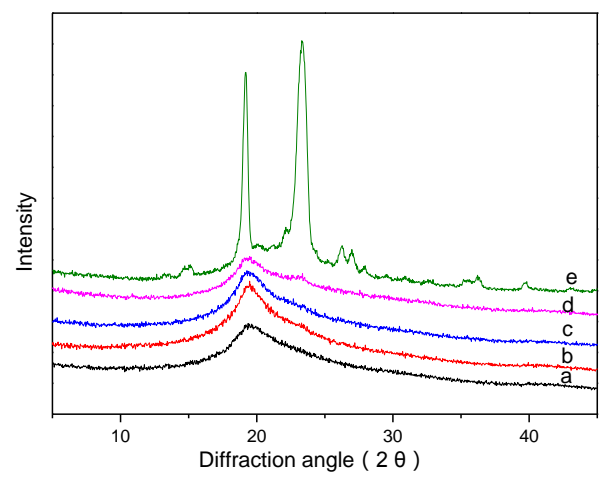

Figure 4. X-ray diffraction of PVA/PEO membranes. (a) $8 \mathrm{wt} \% \mathrm{PVA}$; (b) 8 wt \% PVA $/ 3 \mathrm{wt} \%$ PEO (90/10); (c) 8 wt \% PVA/3 wt \% PEO (80/20); (d) 8 wt \% PVA $/ 3$ wt \% PEO (70/30); (e) 3 wt \% PEO.

\subsection{Morphological Analysis}

The surface morphology and the cross section morphology of the nanofiber membranes with different contents of PEO were presented in Figure 5. We can find that the morphology of fibers changed gradually. In Figure 5A, the fibers were straight, smooth, and even, and they were criss-crossed and intertwined closely as well as the fibers in Figure 5a. As a result, in Figure 6 the surface of the sample was flat and uniform. When added PEO to PVA, the morphology of the fibers, the surface and the internal structure of the films have undergone some changes. Adding a small amount of PEO, in Figure 5B the fibers became uneven, curved with wrinkles appeared. In Figure 5C,D, the adhesion and interlacing between the fibers was more obvious when the content of PEO was increased. This uneven arrangement resulted in larger holes and narrow gaps existing between the fibers. As showed in Figure $5 \mathrm{a}-\mathrm{d}$, the internal construct of films were from dense to fluffy. The fibers changed from reticular to lamellar distribution correspondingly, there were gaps between the layers. When the blending ratios were $80 / 20$ (Figure $5 \mathrm{c}$ ) and 70/30 (Figure 5d), a large amount of solid block structure appeared in the films, it was probably because a large number of fibers adhered together. 


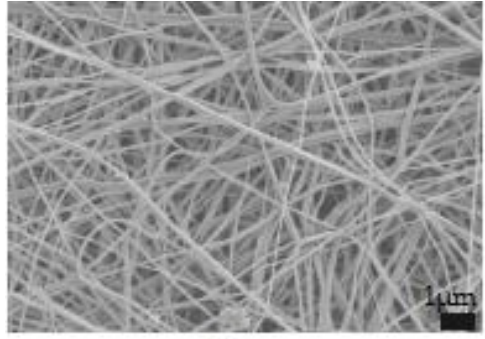

(A)

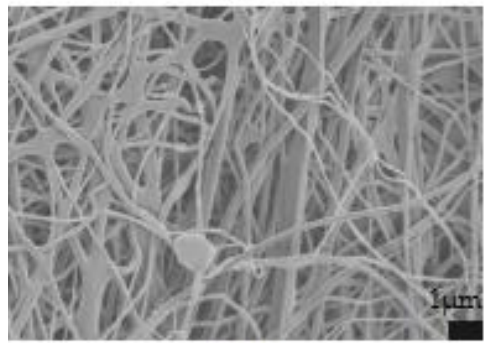

(B)

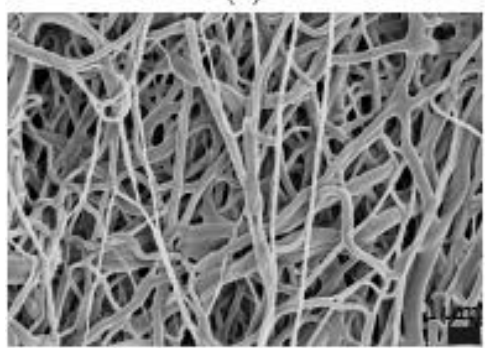

(C)

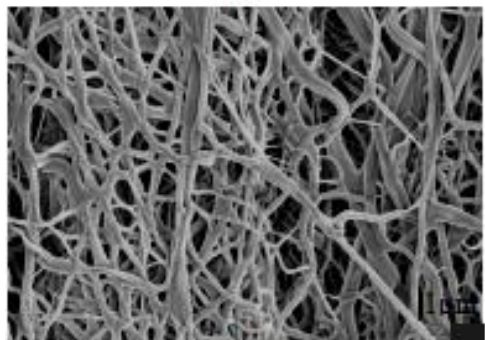

(D)

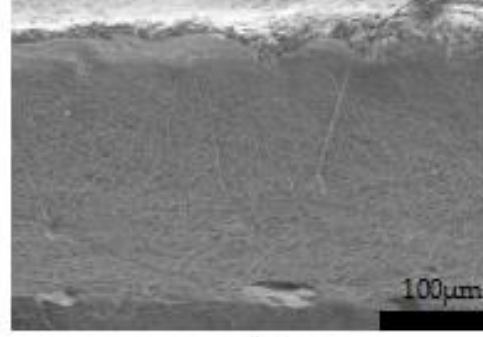

(a)

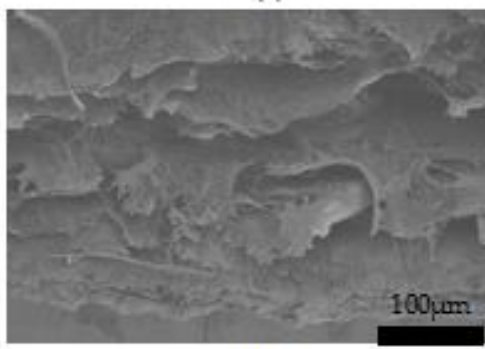

(b)

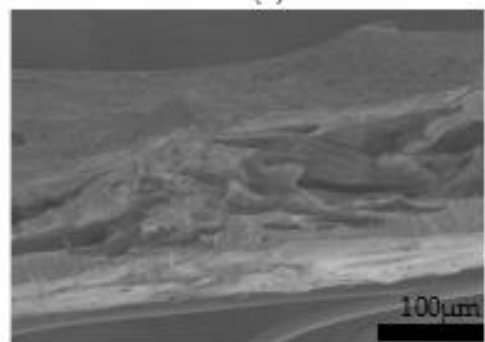

(c)

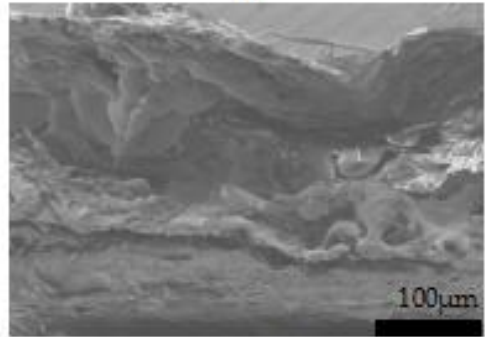

(d)

Figure 5. SEM of surface and cross-section of PVA/PEO membranes. (A)(a) 8 wt \% PVA; (B)(b) 8 wt $\%$ PVA $/ 3$ wt \% PEO (90/10); (C)(c) 8 wt \% PVA /3 wt \% PEO (80/20); (D)(d) 8 wt \% PVA $/ 3$ wt \% PEO $(70 / 30)$.

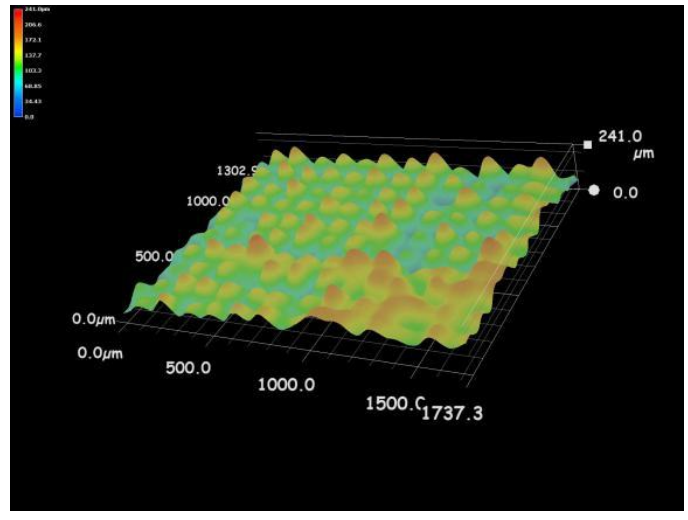

(a)

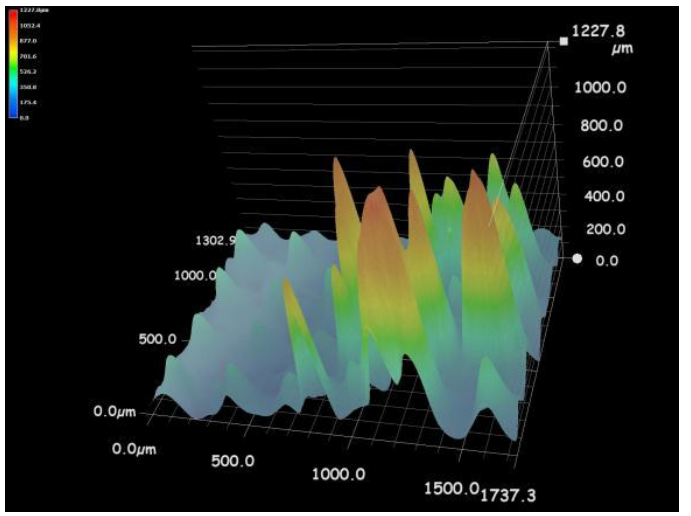

(b)

Figure 6. Cont. 


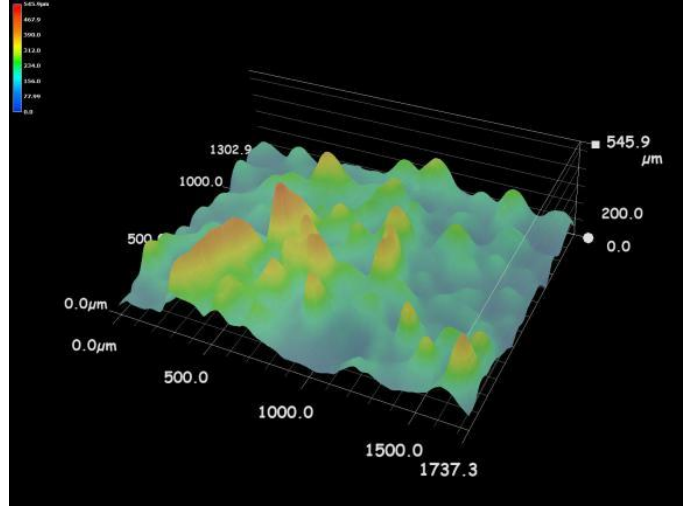

(c)

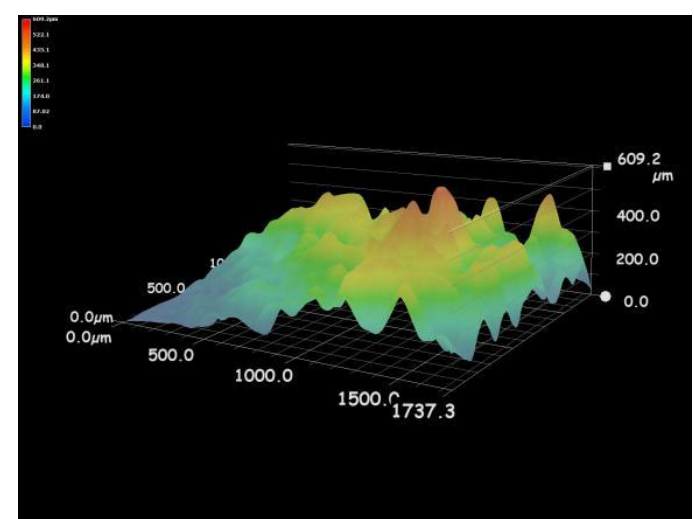

(d)

Figure 6. Depth of field three-dimensional microscopic images of PVA/PEO membranes. (a) 8 wt $\%$ PVA; (b) 8 wt \% PVA $/ 3$ wt \% PEO (90/10); (c) 8 wt \% PVA $/ 3$ wt \% PEO (80/20); (d) 8 wt \% PVA $/ 3$ wt \% PEO (70/30); (e) 3 wt \% PEO.

Electrospun films were composed of numerous intertwined fibers, so the structure of membranes are related to fibers, morphology closely. It can be found from Figure 6, that the surfaces of films were changed from flat to rugged. The height difference of sample a was only $241 \mu \mathrm{m}$, while sample b was up to $1227 \mu \mathrm{m}$, which nearly five times of sample a. However, the convex parts of sample b were distributed unevenly. The convex parts of samples $\mathrm{c}$ and $\mathrm{d}$ were denser and the height differences were $454 \mu \mathrm{m}$ and $609 \mu \mathrm{m}$, respectively. As showed in Figure 5, there were many pores and cavity structures inside the films, it is probably because the addition of PEO changed the morphology and arrangement of fibers. The electrospinning films with uneven surface and cavity structures may be considered a defect, but as a kind of sound-absorbing material, they play an important role.

\subsection{Sound Absorption Properties of Nanofiber Membranes}

Application of electrospun nanofiber membranes was contributed to its ease of manufacture and light weight. They can be used for indoors and automotive decoration to reduce noise. The sound absorption coefficient can be expressed as a percentage ratio of the absorbed sound wave and the incident sound wave. It is called sound absorbing material when its average sound absorption coefficient is greater than 0.2; when its average sound absorption coefficient is more than 0.56 , it is known as excellent sound absorption material [18]. In order to improve the accuracy of results, we tested the sound absorption properties of the nanofiber membrane with the same thickness $(2 \mathrm{~mm})$ and composited with the same kind of needle-punched nonwovens $(4 \mathrm{~mm})$. In this paper, the materials hardly have sound absorption properties over the range of $80-500 \mathrm{~Hz}$, so we mainly studied the sound absorption properties over the range of $500-6300 \mathrm{~Hz}$.

Figure 7 showed that the needle-punched nonwoven had poor sound absorption property, while nano-fiber membranes with a thickness of $2 \mathrm{~mm}$ showed good sound absorption property. The weird thing was that the sound absorption curve trends of sample a and sample $b$ are similar, while as well as sample $\mathrm{c}$ and sample $\mathrm{d}$. It was noticed that sample a showed maximum sound absorption coefficient 0.63 at the frequency of $4000 \mathrm{~Hz}$, sample b reached up to 0.99 at the same frequency. The absorption peak sample $\mathrm{c}$ and $\mathrm{d}$ shifted to low-middle frequency, sample $\mathrm{d}$ showed better sound absorption performance. 


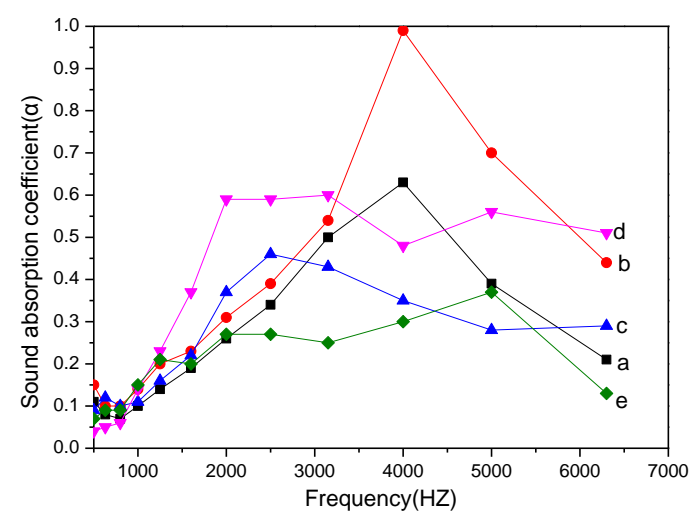

Figure 7. Effect of $2 \mathrm{~mm}$ PVA/PEO membranes sound absorption properties. (a) $8 \mathrm{wt} \% \mathrm{PVA}$; (b) $8 \mathrm{wt} \%$ PVA $/ 3$ wt \% PEO (90/10); (c) 8 wt \% PVA $/ 3$ wt \% PEO (80/20); (d) 8 wt \% PVA $/ 3$ wt \% PEO (70/30); (e) $3 \mathrm{wt} \%$ PEO.

It can be seen from Figure 8 that sound absorption performance of the needle-punched nonwoven had been greatly improved after being compounded with the nanofiber membranes. Because of the increased thickness, the path of the sound waves inside the material became longer thus acoustic energy lost mostly [37,38]. Sample a showed maximum sound absorption coefficient 0.78 at the frequency of $1580 \mathrm{~Hz}$. The sound absorption curves trend of sample b-d were consistent, absorption peaks reached up to $0.78,0.82,0.89$ and $1,0.79,0.91$ at the frequencies of $1000 \mathrm{~Hz}$ and $2000 \mathrm{~Hz}$, respectively. Chen C. et al. studied that more cavity volume, wider frequency band and larger thickness were beneficial for sound absorption. Materials acquired excellent sound absorption at low frequency with a sound wavelength and thickness ratio of 169.9 [39]. Samples a, b, c, and d showed notably better sound absorption performance in the range of 1081-1945, 750-6300, 780-3077, and 750-6300 Hz, respectively. Mohrova J. et al. studied that the coustic absorption band of PVA nanofiber membrane was broadened when the surface irregularity increased [40]. With the addition of PEO, the absorption peak shifted to low-middle frequency, and the sound absorption property was improved in the whole frequency range generally that probably because the blend membranes possessed cavity structure and distributed irregularly. Nanofiber membranes belong to porous structure with high porosity, the vibration of the sound waves entered material drived the vibration of the surrounding air and pores. A large amount of sound energy was consumed along with the viscous friction and heat conduction between the sound waves and the airhole walls.

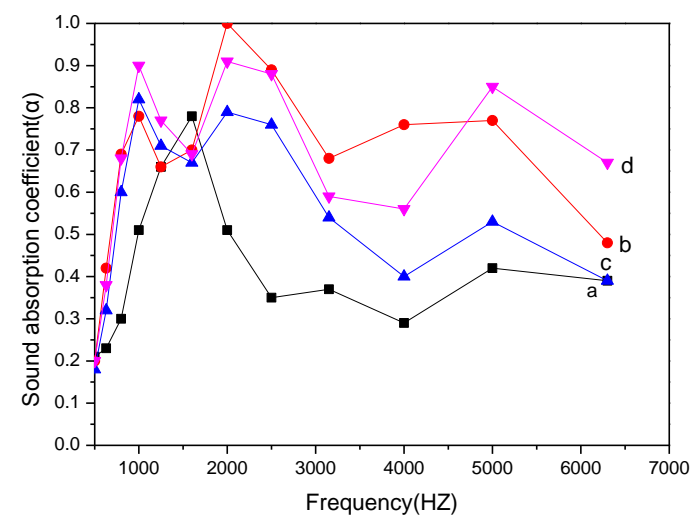

Figure 8. Effect of composite sound absorption properties. (a) composite of $8 \mathrm{wt} \%$ PVA and needle-punched nonwoven; (b) composite of $8 \mathrm{wt} \%$ PVA $/ 3 \mathrm{wt} \%$ PEO (90/10) and needle-punched nonwoven; (c) composite of 8 wt \% PVA/3 wt \% PEO (80/20) and needle-punched nonwoven; (d) composite of $8 \mathrm{wt} \%$ PVA/3 wt \%PEO (70/30) and needle-punched nonwoven. 
The film with $2 \mathrm{~mm}$ thickness was made up of several single layer films. As shown in Figures 5 and 6 , the surface of the blend membranes were irregular and there were a lot of cavities inside the membranes. The resonant structure was formed between the cavities and the membrane walls, which was equivalent to the combination of multiple Helmholtz resonators. When the frequency of the acoustic wave was closed to the natural frequency of the resonant structure, the sound absorption performance was optimal. The depth of the cavity was equivalent to increasing the effective thickness of the materials, increasing the sound absorption area and the acoustic resistance, so that they had a wider absorption band. When the sound wave passed through the surface of the membranes and reached the cavity, the air enclosed in the cavity had a certain elasticity and was regarded as a compressed air packet when propelled by the sound waves. The incoming acoustic waves from the outside and the air bag formed a Helmholtz resonator, which achieved the absorption effect of stimulated resonance at the low-middle frequency. The acoustic energy was mostly lost to the viscoelasticity of air, heat conduction, and relaxation of molecular vibration of air. Air absorption and sound frequency was positively correlated, the higher the frequency and sound attenuation faster. Samples b, c, and d had a large number of internal cavities, which contained more air and absorbed more sound waves, resulting in excellent sound absorption at high frequencies.

\section{Conclusions}

This study confirmed that the addition of PEO to PVA has an effect on the morphology, structure, and sound absorption properties. From the micro perspective, the fibers became uneven and curved, adhesion and interlacing between the fibers was more pronounced. As a result, the surface of the membranes behaved roughly and irregularly, the internal structure of membranes became fluffy with a large number of voids and cavities. Moreover, when the blend ratios were 80/20 and 70/30, a large amount of solid block structure appeared inside the films.

Nanofiber membranes with a thickness of $2 \mathrm{~mm}$ showed better sound absorption property. Sample a showed maximum sound absorption coefficient 0.63 at the frequency of $4000 \mathrm{~Hz}$, sample b reached up to 0.99 at the same frequency. The absorption peak sample c and d shifted to low-middle frequency, sample $\mathrm{d}$ behaved better sound absorption performance. The sound absorption performance of the nanofiber membranes were greatly improved after being compounded with needle-punched nonwoven. Sample a showed maximum sound absorption coefficient 0.78 at the frequency of $1580 \mathrm{~Hz}$. Sample b-d showed consistent trend, absorption peaks reached up to $0.78,0.82,0.89$ and 1, 0.79, 0.91 respectively at frequencies of $1000 \mathrm{~Hz}$ and $2000 \mathrm{~Hz}$. With the addition of PEO, the absorption peak shifted to low-middle frequency, and the sound absorption property was improved in the whole frequency range. To sum up, the absorption band will be wider as the irregularity of the surface and internal fluff of the films increases.

It is revealed that the different morphology and structure of nanofiber membranes have a great impact on the sound absorption performance. In this paper, we mainly discussed the effect of morphology and structure on sound absorption property. Flow resistance, areal density, and porosity are analyzed less. In the future, interaction of multiple factors should be considered on sound absorption properties.

Acknowledgments: This work was supported primarily by the Second Phase of Jiangsu Universities, Distinctive Discipline Development Program for Textile Science and Engineering of Soochow University.

Author Contributions: Huan Liu and Baoqi Zuo conceived and designed the experiments; Huan Liu performed the experiments; Huan Liu and Baoqi Zuo analyzed the data; Baoqi Zuo contributed analysis tools; Huan Liu wrote the paper.

Conflicts of Interest: The authors declare no conflict of interest. 


\section{References}

1. Singh, N.; Davar, S.C. Noise pollution-Sources effects and control. J. Hum. Ecol. 2004, 16, $181-187$. [CrossRef]

2. Campello-Vicente, H.; Peral-Orts, R.; Campillo-Davo, N.; Velasco-Sanchez, E. The effect of electric vehicles on urban noise maps. Appl. Acoust. 2017, 116, 59-64. [CrossRef]

3. Berardi, U.; Iannace, G. Predicting the sound absorption of natural materials: Best-fit inverse laws for the acoustic impedance and the propagation constant. Appl. Acoust. 2017, 115, 131-138. [CrossRef]

4. Fan, C.; Nie, J.K.; Xiao, W.M.; Chen, X.; Han, Y.; Geng, H.J. Research on sound-absorption materials for substation noise reduction. Electr. Power 2014, 47, 144-147.

5. Berardi, U.; Iannace, G. Acoustic characterization of natural fibers for sound absorption applications. Build. Environ. 2015, 94, 840-852. [CrossRef]

6. Peng, L.; Song, B.; Wang, J.; Wang, D. Mechanic and acoustic properties of the sound-absorbing material made from natural fiber and polyester. Adv. Mater. Sci. Eng. 2015, 4, 1-5. [CrossRef]

7. Zhu, X.; Wang, M.; Huang, J.; Peng, L.I.; Zhang, B.; Wen, R.; Liu, Y. Research progress of sound absorption properties of wood-plastic composites. J. For. Eng. 2017, 10-15. Available online: http:/ /www.en.cnki.com. cn/Article_en/CJFiTotal-LKKF201703002.htm (accessed on 16 May 2017). [CrossRef]

8. Luan, Q.; Qiu, H.; Cheng, G.; Liu, X. Sound absorption properties of nonwoven material based on wool and its hybrid fibers. J. Text. Res. 2017, 3, 72-76. Available online: http:/ /www.en.cnki.com.cn/Article_en/ CJFDTotal-FZXB201703013.htm (accessed on 15 March 2017).

9. Gwon, J.G.; Kim, S.K.; Kim, J.H. Development of cell morphologies in manufacturing flexible polyurethane urea foams as sound absorption materials. J. Porous Mater. 2016, 23, 1-9. [CrossRef]

10. Wang, J.; Xi, Z.; Tang, H.; Huang, W.; Zhu, J.; Ao, Q.; Zhi, H. Research status of sound absorption property of porous materials made by metal fiber. Rare Met. Mater. Eng. 2012, 41, 405-408. Available online: http:/ / en.cnki.com.cn/Article_en/CJFDTotal-COSE2012S2099.htm (accessed on 15 September 2012 ).

11. Zhu, J.; Sun, J.; Tang, H.; Wang, J.; Ao, Q.; Bao, T.; Song, W. Gradient-structural optimization of metal fiber porous materials for sound absorption. Powder Technol. 2016, 301, 1235-1241. [CrossRef]

12. Tang, B.; Tang, Y.; Zhou, R.; Lu, L.-S.; Liu, B.; Qu, X.-M. Low temperature solid-phase sintering of sintered metal fibrous media with high specific surface area. Trans. Nonferr. Met. Soc. China 2011, 21, 1755-1760. [CrossRef]

13. Zhang, B.; Chen, T. Calculation of sound absorption characteristics of porous sintered fiber metal. Appl. Acoust. 2009, 70, 337-346.

14. Liu, J.; Bao, W.; Wang, S.; Zuo, B.; Chen, L.; Chen, Z.; Gao, W. The structure design and prediction of noise reduction coefficients of dual layered nonwoven absorbers. Noise Control Eng. J. 2013, 61, 500-508. [CrossRef]

15. Peng, M.; Zhao, X. Application of nanomaterial in sound absorption material. J. Chengdu Text. Coll. 2017, 2, 235-240. Available online: http://www.en.cnki.com.cn/Article_en/CJFDTotal-CDFZ201702051.htm (accessed on 20 April 2017).

16. Israel, T.A.; Schnitta, B.S. Structures Formed with Sheet Material Configured with at Least One Sound Absorbing Layer. Patent US9714508 B2, 14 January 2016.

17. Fan, C.; Tian, Y.; Wang, Z.Q.; Nie, J.K.; Wang, G.K.; Liu, X.S. Structural parameter effect of porous material on sound absorption performance of double-resonance material. IOP Conf. Ser. Mater. Sci. Eng. 2017, 213, 012028. [CrossRef]

18. Yuan, G.H.; Wang, X.C. Research status and prospect of sound absorbing materials. Mech. Eng. 2006, 6, $17-19$.

19. Zhu, R.; Li, J.; Bi, W.; Yang, X. Study on inorganic porous sound absorption materials. J. Univ. Sci. Technol. Liaoning. 2017, 3, 36-41. Available online: http://www.en.cnki.com.cn/Article_en/CJFDTotalASGT201703008.htm (accessed on 15 June 2017).

20. Yang, M.; Sheng, P. Sound absorption structures: From porous media to acoustic metamaterials. Annu. Rev. Mater. Res. 2017, 47, 83-114. [CrossRef]

21. Liu, J.; Bao, W.; Shi, L.; Zuo, B.; Gao, W. General regression neural network for prediction of sound absorption coefficients of sandwich structure nonwoven absorbers. Appl. Acoust. 2014, 76, 128-137. [CrossRef]

22. Cao, X.; Wang, X.; Ding, B.; Yu, J.; Sun, G. Novel spider-web-like nanoporous networks based on jute cellulose nanowhiskers. Carbohydr. Polym. 2013, 92, 2041-2047. [CrossRef] [PubMed] 
23. Toyoda, M.; Sakagami, K.; Okano, M.; Okuzono, T.; Toyoda, E. Improved sound absorption performance of three-dimensional MPP space sound absorbers by filling with porous materials. Appl. Acoust. 2017, 116, 311-316. [CrossRef]

24. Yang, E.; Qin, X.; Wang, S. Electrospun crosslinked polyvinyl alcohol membrane. Mater. Lett. 2008, 62, 3555-3557. [CrossRef]

25. Zhang, L.Z.; Wang, Y.Y.; Wang, C.L.; Xiang, H. Synthesis and characterization of a PVA/LiCl blend membrane for air dehumidification. J. Membr. Sci. 2008, 308, 198-206. [CrossRef]

26. Abdelaziz, M.; Ghannam, M.M. Influence of titanium chloride addition on the optical and dielectric properties of PVA films. Phys. B Condens. Matter 2010, 405, 958-964. [CrossRef]

27. Elashmawi, I.S.; Abdelrazek, E.M.; Hezma, A.M.; Rajeh, A. Modification and development of electrical and magnetic properties of PVA/PEO incorporated with $\mathrm{MnCl}_{2}$. Phys. B Condens. Matter. 2014, 434, 57-63. [CrossRef]

28. Abdullah, O.G.; Saber, D.R.; Hamasalih, L.O. Complexion formation in $\mathrm{PVA} / \mathrm{PEO} / \mathrm{CuCl}_{2}$ solid polymer electrolyte. Univ. J. Mater. Sci. 2015, 3, 1-5.

29. Aziz, S.B.; Abdullah, O.G.; Hussein, A.M.; Abdulwahid, R.T.; Rasheed, M.A.; Ahmed, H.M.; Abdalqadir, S.W.; Mohammed, A.R. Optical properties of pure and doped PVA:PEO based solid polymer blend electrolytes: Two methods for band gap study. J. Mater. Sci. Mater. Electron. 2017, 28, 7473-7479. [CrossRef]

30. Wang, C.-H.; Liu, S.-K.; He, W.-T.; Wang, Y. Preparation and characterization of PVA/PEO blended nanofiber films prepared by electrospinning. J. Tianjin Polytech. Univ. 2015, 4, 36-39. Available online: http:/ /www.en. cnki.com.cn/Article_en/CJFDTOTAL-TJFZ201504007.htm (accessed on 25 August 2015).

31. Abd El-kader, F.H.; Hakeem, N.A.; Elashmawi, I.S.; Ismail, A.M. Enhancement of structural and thermal properties of PEO/PVA blend embedded with $\mathrm{TiO}_{2}$, nanoparticles. Indian J. Phys. 2013, 87, 983-990. [CrossRef]

32. Oraby, A.H.; Hezma, A.M.; Elashmawi, I.S.; Alluheebe, M.A. Verification of the changes in the structural and optical properties of PVA/PEO embedded by lithium chloride. Res. J. Pharm. Biol. Chem. Sci. 2015, 6, 724-734.

33. Meikhail, M.S.; Oraby, A.H.; Farea, M.O.; Abdelghany, A.M. Spectroscopic studies of PVA/PEO hydrogel filled with cesium chloride. Res. J. Pharm. Biol. Chem. Sci. 2014, 5, 976-983.

34. Ragab, H.M. Studies on the thermal and electrical properties of polyethylene oxide/polyvinyl alcohol blend by incorporating of cesium chloride. Results Phys. 2017, 7, 2057-2065. [CrossRef]

35. Lian, Z.; Ye, L. Structure and properties of PVA/PEO hydrogel prepared by freezing/thawing method. J. Thermoplast. Compos. Mater. 2017, 26, 912-922. [CrossRef]

36. Joge, P.; Kanchan, D.K.; Sharma, P.; Gondaliya, N. Conductivity studies on filler free and filler doped PVA-PEO based blend polymer electrolytes. Adv. Mater. Res. 2013, 665, 227-232. [CrossRef]

37. Margaritis, E.; Kang, J. Relationship between green space-related morphology and noise pollution. Ecol. Indic. 2017, 72, 921-933. [CrossRef]

38. Ru, J.; Kong, B.; Liu, Y.; Wang, X.; Fan, T.; Zhang, D. Microstructure and sound absorption of porous copper prepared by resin curing and foaming method. Mater. Lett. 2015, 139, 318-321. [CrossRef]

39. Chen, C.; Du, Z.; Hu, G.; Yang, J. A low-frequency sound absorbing material with subwavelength thickness. Appl. Phys. Lett. 2017, 110, 10-17. [CrossRef]

40. Mohrova, J.; Kalinova, K. Different structures of PVA nanofibrous membrane for sound absorption application. J. Nanomater. 2012, 2, 2449-2464. [CrossRef]

(C) 2018 by the authors. Licensee MDPI, Basel, Switzerland. This article is an open access article distributed under the terms and conditions of the Creative Commons Attribution (CC BY) license (http://creativecommons.org/licenses/by/4.0/). 